\title{
Histopathological Analysis of Gastric Cancers in University of Ilorin Teaching Hospital: A 20-Year Review
}

\author{
Suleiman KA, Afolayan EAO, Ibrahim OOK, Ahmed A, Abubakar-Akanbi SK. ${ }^{2}$ \\ ${ }^{I}$ Department of pathology Federal Medical Centre, Birnin Kebbi, Kebbi state \\ ${ }^{2}$ Department of pathology University of Ilorin Teaching Hospital Ilorin, Kwara state. \\ ${ }^{3}$ Department of Community Medicine and Primary Care. Federal Medical Centre, Abeokuta Ogun state.
}

*Correspondence: Dr KA Suleiman

Email: suleimankbr@gmail.com

\author{
Article information \\ Date Submitted: $\quad 3 / 1 / 2021$ \\ Date Accepted: $\quad$ 20/3/2021 \\ Date Published: $\quad$ 19/4/2021
}

\begin{abstract}
Gastric cancer is a relatively common malignancy in Nigeria. Gastric cancer varies from region, being 4th to 20th in proportion to other malignancies. The symptom and signs are often non-specific with the early stages of the disease. This may be responsible for late presentation and poor prognosis. This is a 20-year retrospective analysis of 107 histopathologically confirmed gastric cancers in the department of pathology. This study aimed to analyze the Histopathological patterns of all the gastric cancer cases diagnosed in U.I.T.H Ilorin, over a twenty-year period. Gastric cancers were classified according to WHO 2010 and Lauren classification of gastric cancers. A total of 107 cases of gastric cancers diagnosed, that met the inclusion criteria, were analyzed with male: female ratio of $1.3: 1$ out of which epithelial malignancy accounted for $93.5 \%$ with tubular adenocarcinoma representing the commonest epithelial subtype. Epithelial malignancy is the commonest histological type in this area. Therefore, it is recommended that patients above 40 years with dyspepsia and other alarm features should undergo routine endoscopic screening.
\end{abstract}

Keywords: Gastric cancer, Epithelial malignancy, Histopathological, Poor prognosis.

\section{INTRODUCTION}

G astric cancer is malignant neoplasm that arises in the stomach. It still remains a major health burden globally despite its declining incidence. ${ }^{1}$ It is the fourth commonest cancer in the world with 985,600 new cases diagnosed annually and about 738,000 patients died yearly from the disease making it the second commonest cause of cancer related death. ${ }^{2}$ Gastric cancers is a heterogeneous disease with various histopathological and epidemiological characteristics. Epithelial malignancy is the commonest histological type in about $95 \%$ of cases and there is interplay between the genetics and environmental factors in the pathogenesis of the

\section{How to cite this article}

Suleiman KA, Afolayan EAO, Ibrahim OOK, Ahmed A, Abubakar-Akanbi SK. Histopathological Analysis of Gastric Cancers in University of Ilorin Teaching Hospital: A 20-Year Review. J Biomed Res Clin Pract. 2021;4(1):85-95. doi.org/10.46912/jbrcp.181

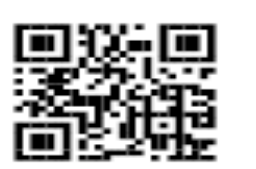

Access to the article website: http://www.jbrcp.net do: : https://doi.org/10.46912/jbrcp.181 
gastric cancer. ${ }^{3}$ Most patients present late because of the non- specific nature of its symptoms and signs and the prognosis is fatal in most cases. ${ }^{4}$ Metastatic tumour to the stomach is rare although lung and breast are the commonest primary sites and lymphatic spread is more favoured over haematogenous route. ${ }^{5}$

Gastric cancer is the fourth commonest cancer in the western world after cancers of the lungs, breast and colorectal. ${ }^{6}$ Worldwide, it is the second most common cancer of the gastro-intestinal tract, following adenocarcinoma of the colon. ${ }^{7}$ It is relatively low in the developing world, Nigeria inclusive. ${ }^{6}$ In Nigeria, there is a regional variation in prevalence of gastric cancers. ${ }^{8}$ In Ibadan, it is ranked fourteenth commonest cancers whereas in Ilorin, it occupied eleventh position of all cancers cases diagnosed. ${ }^{9,10}$ However in Zaria, using data from the cancer registry, gastric cancer is the twentieth commonest cancers. ${ }^{11}$ while in Calabar it is the fourth commonest cancer. ${ }^{12}$

Gastric cancer usually occurs in adults but most commonly diagnosed at age 50 years and above. ${ }^{13}$ Though gastric Cancer is rare in children and adolescent, it has been reported in Ile-Ife in a 7-year-old child. ${ }^{14}$ The malignancy occurs in both sexes though males are more affected than females. ${ }^{7,13}$ Male to Female ratio is usually in the range of $1.2: 1$ to $2: 1$. $^{8,15,16}$

Carcinoma is the commonest histological type of gastric cancer accounting for over $90 \%$ of gastric cancer cases, ${ }^{7,16}$ while mesenchymal tumour, non-Hodgkin's lymphoma and carcinoid tumour represent $7.6 \%, 1 \%$ and $1 \%$ respectively in some study. ${ }^{16}$

Most patients with gastric cancers present late because the symptoms of early gastric cancer is non-specific and lack of routine endoscopic screening and biopsy also contribute to the late presentation. ${ }^{8,17}$ Furthermore, endoscopic diagnosis of early cancers are more difficult because it usually shows subtle features of gastritis. ${ }^{18}$ The endoscopic findings of advanced gastric cancer includes, a well demarcated lesion, irregularity in colour and surface patterns and microvascular pattern with demarcation lines. ${ }^{18}$
The prognosis of gastric cancer remains poor worldwide with overall five-year survival rate of all patients diagnosed with gastric cancer between $4 \%$ and $13 \%{ }^{7,8,19,20}$ However, the prognosis of early gastric cancer is fair with five-year survival of about $80 \%$ or more. $^{21}$

\section{MATERIALS METHODS}

The study was a retrospective descriptive type conducted in the pathology department of University of Ilorin teaching hospital assessing data from 1991 to 2010 .

Records of all cases of gastric cancers within the study period were retrieved from the surgical pathology bench register. The demographic characteristics such as age and sex of all patients were extracted from the histopathology register and request forms. The Haemotoxylin and Eosin (H\&E) stained slides of the corresponding cases were retrieved and reviewed. Fresh sections were cut for faded, broken and lost slides from the retrieved paraffin-embedded tissue blocks and were stained with $\mathrm{H}$ and $\mathrm{E}$ stains. Histochemical stains like modified Giemsa stain for H.pylori, periodic acid Schiff diastase for mucin, reticulin stain for lymphomas, Phosphotungstic Acid-Haemotoxylin (PTAH) for skeletal muscle, and Mason trichrome, to differentiate fibrocollagenous tumour (e.g. fibrosarcoma) from muscle fibres, were used accordingly. Immunohistochemistry on malignant lymphoma and H.pylori could not be conducted because the facilities are just being developed in our centre.

\section{Sample size}

The study was a retrospective work over a 20-year period. There were 115 cases of gastric cancer diagnosed within the study period of which 107 met the inclusion criteria and were reviewed for the study.

\section{Inclusion criteria}

All registered cases of gastric cancers, with the 
necessary data for this study, diagnosed histologically in the Department during the study period were included in the study.

\section{Exclusion criteria}

Cases where either the slides, paraffin-embedded tissue blocks nor the pathology request forms could not be found were all excluded from this study.

\section{Data analysis}

Data obtained were analysed using the computer software statistical package for social sciences (SPSS) version 20. Gastric cancers were classified according to WHO 2010 classification and Lauren's classification of gastric cancers. Data obtained in this study were presented in prose, tables, charts and photomicrographs of representative neoplasms are presented in some cases.

\section{Ethical consideration}

The approval of the hospital ethical committee was obtained before the commencement of this study.

\section{RESULTS}

Out of the total 516 gastric samples received over the period of study, $115(22.3 \%)$ were histologically diagnosed as gastric cancers. During the same period of study, 3,806 cancer cases were histologically diagnosed at our centre out of which gastric cancers accounted for $3 \%$ with 115 cancer cases (Figure 1 ).

Out of the 107 cases of gastric cancers analysed, there were $61(57 \%)$ males and $46(43 \%)$ females giving a Male to Female ratio $1.3: 1$. The age of the patients with gastric cancers ranged from 20 years to 85 years, and modal age range of 51-60 years with a total of $24(22.4 \%)$ cases (table 1).

Out of the total 107 cases of gastric cancers under review, epithelial malignancies topped the list and accounted for $100(93.5 \%)$ cases, malignant lymphoma represented 4 (3.7\%) cases while mesenchymal malignancy accounted for $3(2.8 \%)$ cases. There was no case of metastatic cancer seen in this study (table 2).

Mesenchymal malignancies accounted for 3 (2.8\%) cases of total gastric cancers and all were Leiomyosarcoma.

Using Lauren's criteria, there were 63 cases of intestinal type of gastric carcinoma with $36 \%$ cases and $27 \%$ cases diagnosed in males and females respectively. The diffuse type was reported in 30 patients with $17 \%$ cases in males and $3 \%$ cases in females while indeterminate variants accounted for 7 cases with $4 \%$ and $3 \%$ in males and females respectively (table 3 ).

Using the number grading system there were 52 gastric cancers cases that could be graded. There were 11 cases of grade 1 (well differentiated adenocarcinoma) accounting for $21.2 \%$ of the cases. Grade 2 (moderately differentiated adenocarcinoma) was the commonest with $28(53.8 \%)$ cases while Grade 3 (poorly differentiated adenocarcinoma) represent 13 (25\%) cases. Hence both moderate and poorly differentiated adenocarcinoma (Grade 2 and 3 ) constituted about $80 \%$ of all the cases.

Table 1: socio-demographic characteristics of Patients with Gastric Cancer at U.I.T.H Ilorin

\begin{tabular}{lllll}
\hline Age & \multicolumn{2}{l}{ Frequency } & Total & Percentage (\%) \\
& Male & Female & & \\
\hline$<10$ & - & - & - & - \\
$11-20$ & 1 & - & 1 & 0.9 \\
$21-30$ & 1 & 3 & 4 & 3.7 \\
$31-40$ & 11 & 9 & 20 & 18.9 \\
$41-50$ & 12 & 10 & 22 & 20.6 \\
$51-60$ & 16 & 8 & 24 & 22.4 \\
$61-70$ & 14 & 9 & 23 & 21.5 \\
$71-80$ & 6 & 5 & 11 & 10.3 \\
$>81$ & - & 2 & 2 & 1.9 \\
Total & 61 & 46 & 107 & 100 \\
\hline
\end{tabular}


Table 3: Showing Lauren's classification of Gastric cancer

\begin{tabular}{llccc}
\hline Histologic type & Male & Female & Total & Percentage \\
\hline Intestinal type & $36(36 \%)$ & $27(27 \%)$ & 63 & $63 \%$ \\
Diffuse type & $17(17 \%)$ & $13(13 \%)$ & 30 & $30 \%$ \\
Indeterminate type & $4(4 \%)$ & $3(3 \%)$ & 7 & $7 \%$ \\
\hline
\end{tabular}

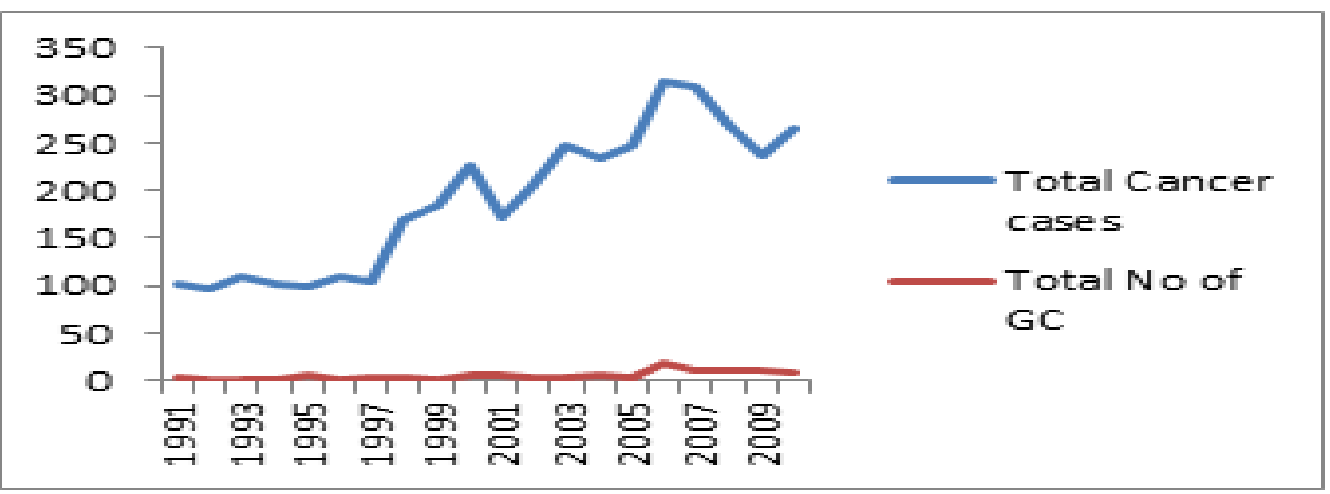

Figure 1: Line graph showing the yearly occurrence of gastric cancer at U.I.T.H Ilorin.

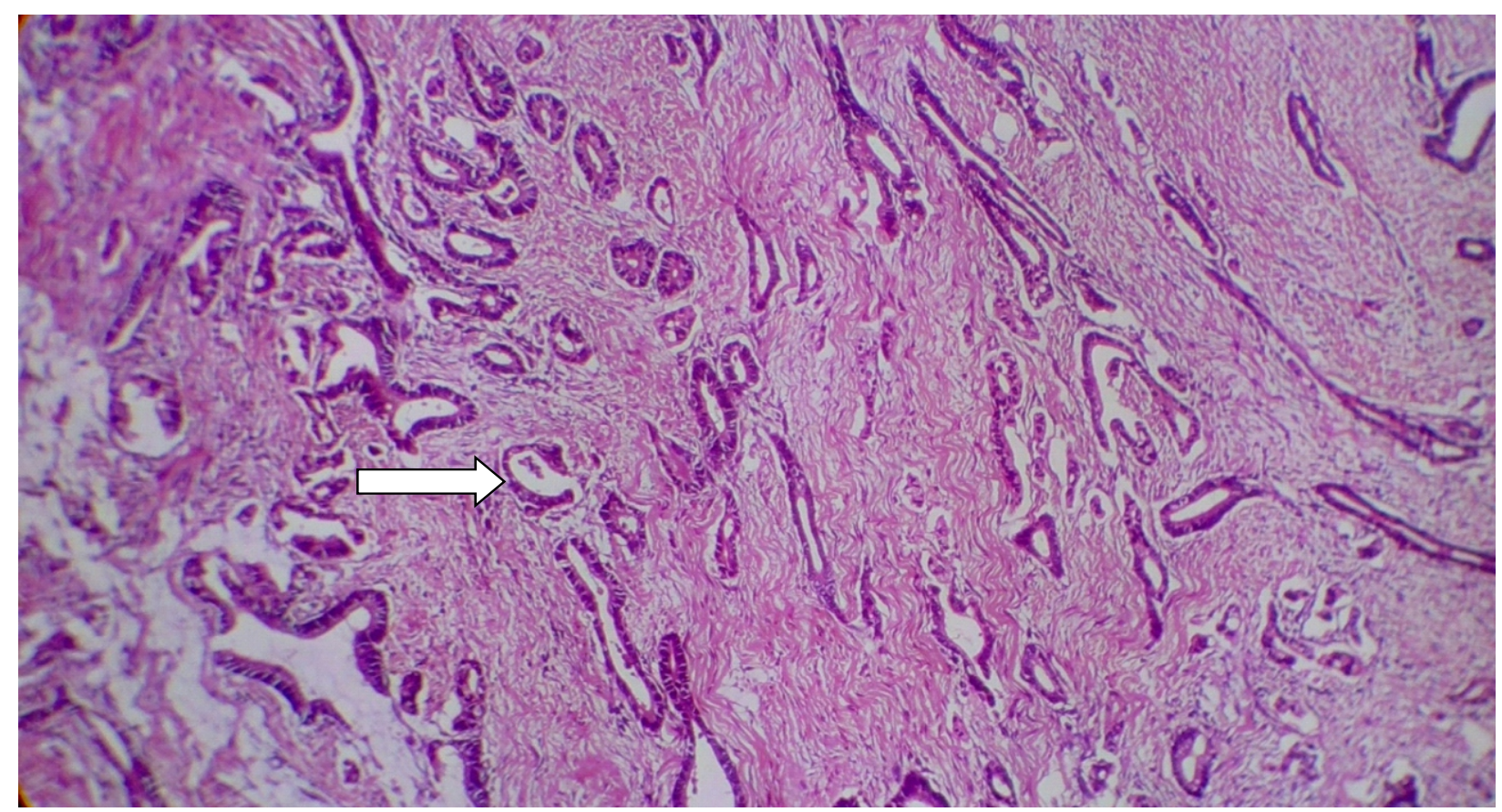

Figure 2. Gastric biopsy showing Tubular Adenocarcinoma with neoplastic cells arranged in tubular patterns (arrow). H\&E X 150. 


\begin{tabular}{lllll}
\hline Histological type & \multicolumn{2}{c}{ Frequency } & Total & Percentage (\%) \\
& Male (\%) & Female (\%) & & \\
\hline Epithelial type & & & & \\
Tubular adenocarcinoma & $30(28)$ & $20(18.7)$ & 50 & 46.7 \\
Signet ring Adenocarcinoma & $17(15.9)$ & $13(12.2)$ & 30 & 28.1 \\
Mucinous Adenocarcinoma & $6(5.6)$ & $5(4.7)$ & 11 & 10.3 \\
Carcinosarcoma & $1(0.9)$ & $2(1.9)$ & 3 & 2.8 \\
Undifferentiated carcinoma & $2(1.9)$ & $1(0.9)$ & 3 & 2.8 \\
Papillary Adenocarcinoma & ---- & $2(1.9)$ & 2 & --- \\
carcinoid & $1(0.9)$ & --- & 1.9 & 0.9 \\
Others e.g Hepatoid & $57(53.2)$ & $43(40.3)$ & 100 & 93.5 \\
Lymphoma & & & & \\
Lymphoma (NHL) & $1(0.9)$ & $1(0.9)$ & 2 & 1.8 \\
Lymphoblastic lymphoma & $1(0.9)$ & - & 1 & 0.9 \\
Small cell lymphoma & -- & $1(0.9)$ & 1 & 0.9 \\
Diffuse large cell lymphoma & --- & ---- & --- & --- \\
Others e.g Burkitt & $2(1.8)$ & $2(1.8)$ & 4 & 3.6 \\
Subtotal Mesenchymal & $2(1.8)$ & $1(0.9)$ & 3 & 2.8 \\
Leiomyosarcoma & -- & ---- & --- & --- \\
Other fibrosarcoma & $2(1.9)$ & $1(0.9)$ & 3 & 2.8 \\
Subtotal metastasis & ----- & ----- & ---- & ---- \\
Total & $\mathbf{6 1}$ & $\mathbf{4 6}$ & $\mathbf{1 0 7}$ & $\mathbf{1 0 0}$ \\
\hline
\end{tabular}




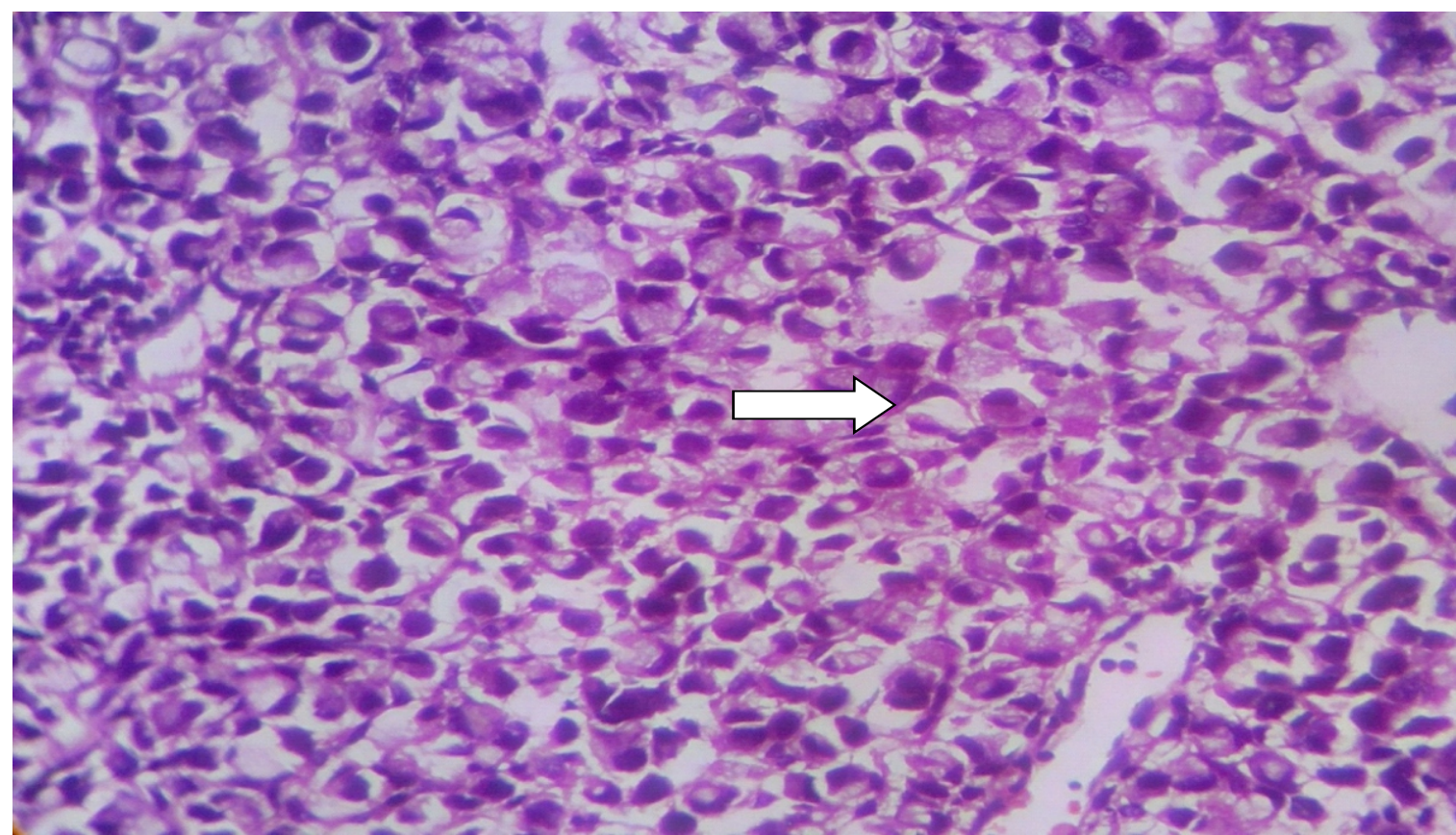

Figure 3. Gastric biopsy showing Signet Ring Adenocarcinoma with sheets of signet ring cell s (arrow). H\&E X150

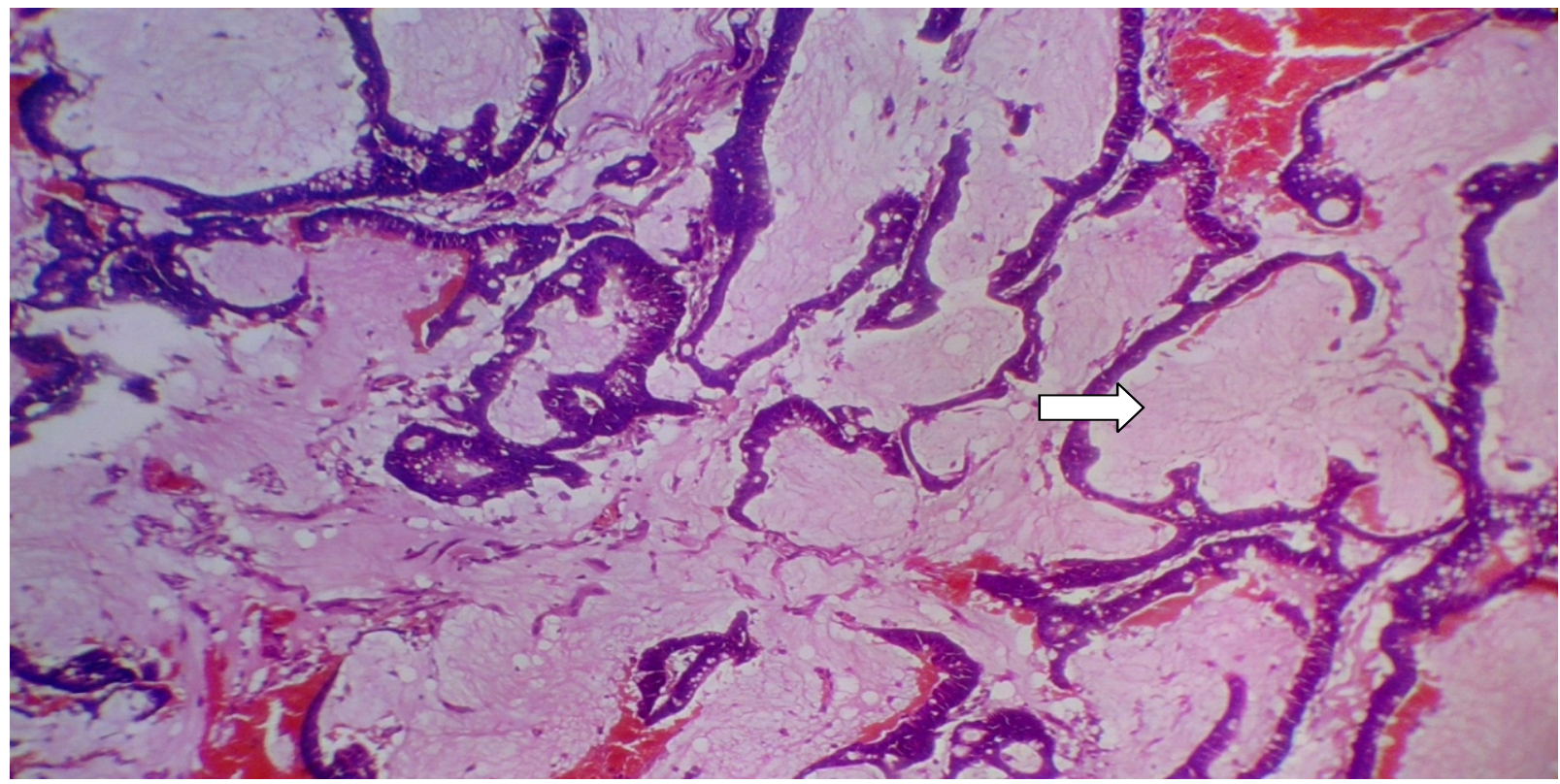

Figure 4 Mucinous Adenocarcinoma of stomach showing neoplastic cells floating in the lakes of extracellular mucin (arrow) H\&E X200 


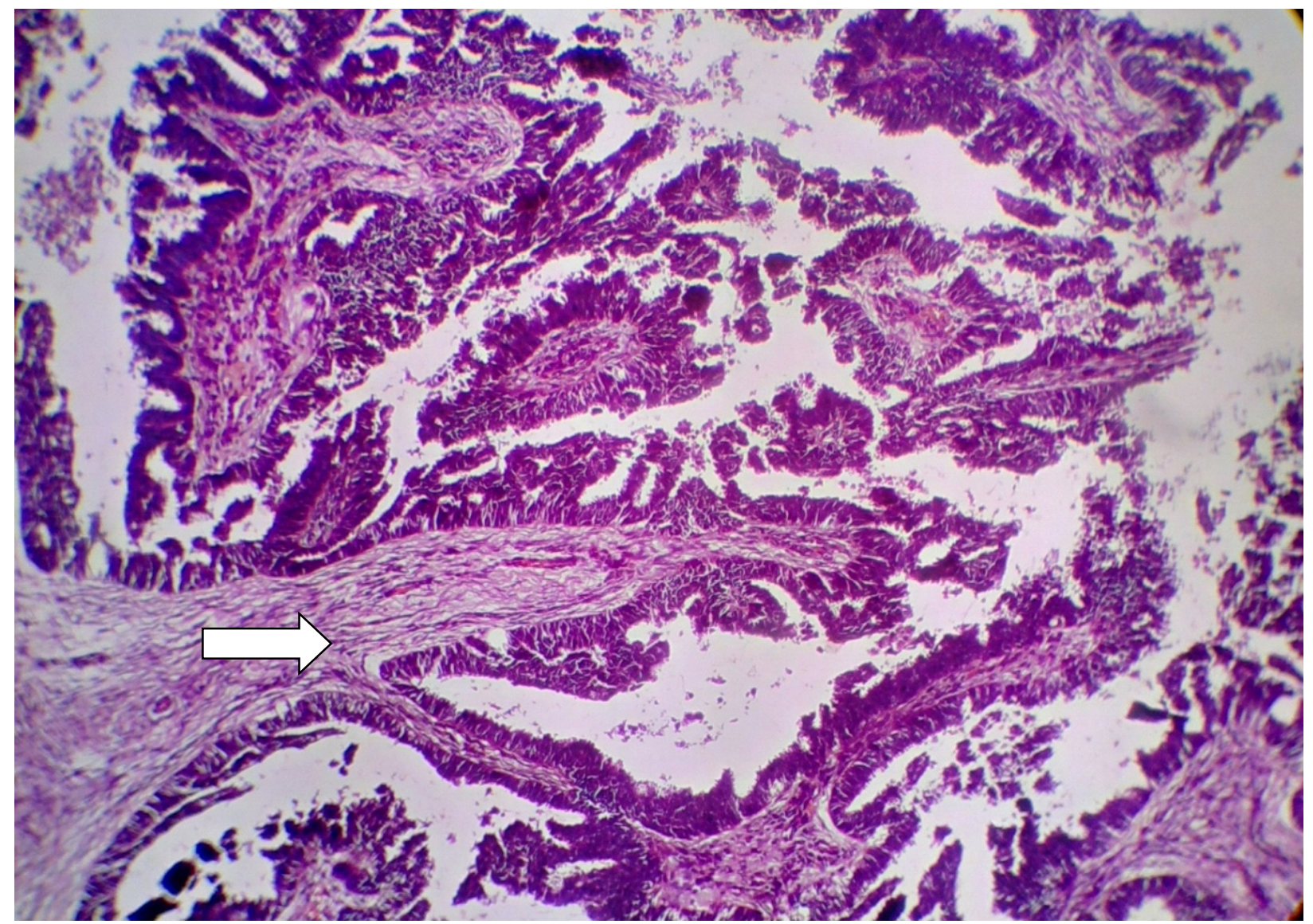

Figure 5. Papillary adenocarcinoma of the stomach showing papillary fronds with fibrovascular core (arrow). Gastric biopsy H\&E X 200

\section{DISCUSSION}

In this study, average of 5 cases of gastric cancer were recorded per annum. This is comparable to an average of 4 and 8 cases per annum reported in Maiduguri and Lagos. ${ }^{8,16}$ Reports from other African countries and developed countries shows higher annual cases of 20-31 and 67-120 per annum respectively. ${ }^{22-26}$ The reason for this disparity may be partly attributable to geographical variation and availability of facilities for the screening and diagnosing of gastric cancer.

Gastric cancers accounted for 3\% of all 3,806 cancers diagnosed within the 20 year period of study corroborating the $2.2 \%$ obtained in an earlier study in our Centre, ${ }^{10}$ and $2 \%$ obtained in Maiduguri. ${ }^{8}$ This study is also in concordance with $3.6 \%$ reported in Jos, ${ }^{27}$ In contrast, gastric cancer represented $1.1 \%$ in Zaria and $4.1 \%$ each in Ibadan and Ife-Ijesha respectively. ${ }^{11,15,28}$ The highest frequency of gastric cancer was 8.4\% recorded in Calabar. ${ }^{12}$

There is a slight male preponderance in this study with $\mathrm{M}: \mathrm{F}$ ratio of $1.3: 1$. This is comparable to $1.4: 1$ each in 
Zaria, and Ibadan and 1.2:1 each in Maiduguri, and Ile-Ife respectively. ${ }^{8,19,14,29}$ In contrast, there is a slightly high ratio of 2:1 in Lagos, and 2.4: 1 in Jos. ${ }^{16,27}$

The youngest age at diagnosing gastric cancer in this study is 20 years, this is in tandem with 22 years recorded in Maiduguri. ${ }^{8}$ Gastric cancers are very rare in young age and the occurrence of cancer at this age is most likely as a result of genetic predisposition of the affected individuals. ${ }^{30}$ The rarity of gastric cancer before age 20 is also supported by findings obtained in studies conducted in Middle East and United States with $0.1 \%$ of cases occurring before the age of 20 years. ${ }^{31,32}$

The oldest age of gastric cancer in this study was 85 years, this is in agreement with 80 years obtained in a study in Ile-Ife. ${ }^{14}$ Gastric cancer is very rare in the elderly people and this assertion was supported by the fact that 2 cases were reported in the age 80 years and above in this study, the finding which is similar to the finding in Ile-Ife in which only 2 cases were reported above 80 years. ${ }^{14}$ The modal age of the disease in this study is $6^{\text {th }}$ decade in which $22.4 \%$ cases of gastric cancers were diagnosed. This is similar to findings by komolafe et al, ${ }^{14}$ and Bakari et al, ${ }^{8}$ where modal age of diagnosing gastric cancer was $6^{\text {th }}$ decades. In United State the peak age was found to be $7^{\text {th }}$ decade and $6^{\text {th }}$ decades in both Japan and China which accounted for more than half of the global burden of the disease. $^{33-35}$

The finding in this study that epithelial malignancy, carcinoma is the commonest histologic gastric cancer concurs with findings in other previous studies from Nigeria. ${ }^{8,14,16}$ In this study epithelial malignancy accounted for $93.5 \%$ of all the total gastric malignancy. Komolafe et al, ${ }^{14}$ reported that $93.5 \%$ were carcinoma while Abdulkareem et al, Bakari et al, and Irabor et al, reported carcinomas in $90 \%, 90.3 \%$ and $91.9 \%$ of all gastric cancers from Lagos, Maiduguri and Ibadan respectively. ${ }^{8,16,29}$ Similarly carcinomas represented $78 \%$, $90 \%$ and $95.3 \%$ of all gastric cancer cases reported from Tanzania, Morocco and Senegal respectively. ${ }^{36-38}$ Also studies from Asia, Europe and America reported that adenocarcinomas are seen in more than $90 \%$ of gastric cancers studied. ${ }^{21,33,39,40}$ It is therefore clear that gastric carcinoma is the commonest histologic type of gastric malignancy worldwide.

There is paucity of information locally on the histopathological patterns of gastric cancers as majority of studies on gastric malignancies are mainly clinical based.

Out of the 100 cases of epithelial malignancy, $50 \%$ were tubular adenocarcinoma subtype and accounted for the commonest epithelial subtype in this series (figure 2). This is similar to the findings in Ile-Ife where tubular adenocarcinoma was the commonest histological subtype and second most common histological subtypes in a study done in Tanzania. ${ }^{14,36}$ Our finding corroborate the report from Iraq and New York in which tubular adenocarcinoma was reported in $54.9 \%$ and $42 \%$ respectively. ${ }^{41,42}$

Signet ring carcinoma accounted for $28.1 \%$ of epithelial subtypes in this study (figure 3). Our figure is higher compared to reports from other studies. In Ile-Ife signet ring carcinoma was reported in $8.8 \%$, in Tanzania it was $9 \%$ and $18 \%$ in Japan. ${ }^{14,36,40}$ However in a study by Alaa et al in Iraq, $^{41}$ signet ring carcinoma accounted for $25.8 \%$, a figure comparable to the finding in this study while a higher value of $37 \%$ was recorded in New York. ${ }^{42}$ Mucinous adenocarcinoma represents $10.3 \%$ of all gastric malignancies reported (figure 4) and is lower than $21.3 \%$ obtained in Ile-Ife. ${ }^{14}$ The finding in this study is about four times lower than $46.2 \%$ obtained in Tanzania and almost four to five times higher than $2 \%$ and 3\% obtained in Iraq and Japan. ${ }^{36,40,41}$ The variation in the values may be as a result of different geographical location of studies. Carcinosarcoma accounted for $2.8 \%$ of all epithelial subtype. This value is greater than $0.4 \%$ obtained by in Ibadan, ${ }^{29}$ and $0.9 \%$ by Ikeda et al. ${ }^{55}$ Undifferentiated carcinoma subtype represents $2.8 \%$ of cases in this study which is lower than $15.4 \%$ obtained in Tanzania. ${ }^{36}$ Papillary adenocarcinoma accounted for $1.9 \%$ of cases (figure 5). The value obtained is lower than findings in Ile-Ife, Tanzania and Japan where $13.7 \%, 13.6 \%$ and $6 \%$ cases of papillary adenocarcinoma were reported respectively. ${ }^{14,36,40}$ 
Uefuchi et al and Hirota et al, reported $6 \%$ and $11 \%$ respectively which are also higher than $1.9 \%$ reported in this study ${ }^{44,45}$ Carcinoid tumour subtype represents $0.9 \%$ of the total epithelial malignancies. The finding in this study is in agreement with findings in Lagos, ${ }^{16}$ and Tanzani, ${ }^{36}$ and about three times lower than $2.5 \%$ obtained in Ibadan. ${ }^{29}$ The malignant lymphomas in this study accounted for $3.7 \%$ of all gastric malignancies and all the cases are of Non-Hodgkin lymphoma. In the literature the highest frequency was reported from Ibadan with $6.1 \%$ while in Lagos Non-Hodgkin Lymphoma accounted for $1 \%$ of all gastric cancers which is almost four times lower than the value obtained in this study. ${ }^{16,46}$ Histologically, the Non-Hodgkin Lymphoma in this study is comprising of lymphoblastic lymphoma $1.8 \%$, small cell lymphoma $0.9 \%$ and diffuse large cell lymphoma $0.9 \%$. A higher value of $5.8 \%$ of diffuse large cell lymphoma was obtained in a study by Alaa et al in Iraq. ${ }^{41}$

Mesenchymal malignancy represents $2.8 \%$ of all the gastric malignancies studied. This value tallies with $3.7 \%$ obtained in a study conducted in Ibadan, ${ }^{29}$ and 2.8\% obtained in Ile-Ife. ${ }^{14}$ In Lagos $7.6 \%$ of the cases studied were mesenchymal tumours while malignant stromal tumours accounted for $6.1 \%$ of all gastric malignancies cases seen in Ibadan. ${ }^{16,46}$ In Mali and Morocco 0.9\% and $3.2 \%$ of their cases were mesenchymal malignancy respectively. ${ }^{37,47}$ All the mesenchymal malignancies seen in this study were leiomyosarcoma and represents $2.8 \%$ of all gastric malignancies. This value is in agreement with 3\% obtained in Ibadan and higher than $1 \%$ obtained in India. ${ }^{29,48}$

There is no case of secondary malignancy to the stomach in all the cases seen in this study. This finding is also common in most of the studies done in other centres. ${ }_{14,16,29,36}$ The implication of this is that stomach is not a common site for metastasis.

\section{CONCLUSION}

This study has shown that gastric cancer is a relatively common malignancy in Nigeria; they are mostly of moderately and poorly differentiated adenocarcinoma. The disease is characterized by non-specific gastrointestinal symptoms with late clinical presentation often in an advanced stage. Epithelial malignancy is the commonest histological type.

\section{Recommendations}

In order to reduce the mortality and morbidity of gastric cancer, early detection of gastric cancer is therefore recommended. This is because gastric cancer is characterized by non-specific symptoms hence its late clinical presentation, it is therefore recommended that patients above 40 years with dyspepsia and other alarm features should undergo routine endoscopic screening.

Conflict of interest: There is no conflict of interest whatsoever in this work.

\section{REFERENCES}

1. Dimitrios HR, Niki JA, Michael F, Angelos MK. Gastric cancer: Introduction, Pathology, Epidemiology . Gastric Breast Cancer 2002;1 (1) $: 1-3$

2. Parkin DM, Bray F, Ferlay J, Pisani P. Global cancer statistics, 2002. CA Cancer J Clin 2005;55:74-108.

3. Manish AS, Raya K, David PK. Molecular classification of Gastric Cancer: A new paradigm. Clin Cancers Res 2011; 17(9): 2693-2701.

4. Fenoglio C, Carnerio F, Correa P, Guilford P, Lambert R, Megraud G et al. Gastric Carcinoma WHO Classification of Tumour IARC Press Lyon 2000 pg 36,39,41.

5. Campoli PM, Ejima FH, Cardoso DM, Silva QO, Santana Filho JB, Queiroz Barreto PA et al. Metastatic cancer of the stomach. Gastric cancer 2006;9:19-25.

6. Parkin DM, Pisani P, Ferlay J. Estimates of the worldwide incidence of 25 major cancers in 1990. Int. J. Cancer. 1990; 80:827-41. 
7. Jerrold RT. The gastrointestinal tract; In Kumar V. Abbas AK, Fausto N, Aster JC, editors. Robbins and Cotran Pathologic Basis of Disease. $8^{\text {th }}$ ed, Elsevier Sauders Inc. Philadelphia 2010: p784-785.

8. Bakari AA, Ibrahim AG, Gali BM, Dogo D, Nggada HA. Pattern of gastric cancer in North-Eastern Nigeria: A Clinicopathological study. Journal of Chinese Medicine 2010; 5(4):4.

9. Ogunbiyi JO, Ladipo AA. Cancer Incidence and Top Ten Cancers in Eleven Local Government Areas in Ibadan and Its Environs, 2004-2008: Ibadan Cancer Registry, Nigeria Technical Report, 2010.

10. Afolayan EAO, Ibrahim OOK, Ayilara GT. Cancer patterns in Ilorin: An analysis of Ilorin cancer registry statistics. Trop J Health Sci 2012; 19(1):42-46.

11. Afolayan AA. Cancer in the North-Western region of Nigeria: An update analysis of Zaria cancer registry data. Western Nigeria Journal of medical science 2008;1(1):37-43.

12. Ekanem IO. Calabar cancer registry; In Parkin DM, Ferlay J, Hamdi-Cherif M, Sitas F, Thomas JO, Wabinga et al editors. Cancer in Africa: Epidemiology and Prevention. International Agency for Research on Cancer (IARC) Lyon 2003; 95.

13. Catalano V, Labianca R, Beretta GD, Gatta G, De Braud F, Van Cutsem E. Gastric cancer. Crit Rev Oncol Hematol 2005;54:209-41.

14. Komolafe AO, Ojo OS, Olasode BJ. Gastric malignancies and associated pre-malignant lesions in a teaching hospital in South-West Nigeria. African Journal of Biotechnology. 2008;7(13)2104-11.

15. Oluwasola AO, Ogunbiyi JO. Gastric carcinoma: Etiological, Clinicopathological and management patterns in Nigeria. Niger J Med. 2003;12(4):177-186.

16. Abdulkareem FB, Onyekwere CA, Awolola NA, Ajekigbe AT. Clinicopathological review of malignant gastric tumours in Lagos, Nigeria. Nig Q J Hosp Med. 2010;20(2):49-54.

17. Parkin DM, Bray FI, Devesa SS. Cancer burden in the year 2000. The global picture. Eur J Cancer 2001; 37 (8):4-66.
18. Kenshi Y. The endoscopic diagnosis of early gastric cancer. Ann Gatroenterol 2013; 28 (1):65-67.

19. Ahmed A, Ukwenya AY, Makama JG, Mohammed I. Management and outcome of gastric carcinoma in Zaria, Nigeria. Afr. Health Sci. 2011;11(3):353-61.

20. Abdulkareem FB, Faduyile FA, Daramola AO, Rotimi O, Banjo AAF, Elesha SO et al. Malignant Gastrointestinal Tumours in South-Western Nigeria: A Histopathologic Analysis of 713 Cases. West Afr. J. Med 2009;28(3):173-8.

21. Juan R. Gastrointestinal tract; In Juan R. editor. Rosai and Ackerman's surgical pathology $10^{\text {th }} \mathrm{ed}$, Mosby Elsevier Inc. China 2011:615-16.

22. Niang A, Mbengue M, Diouf ML, Diouf B, Ka MM, Pouye A et al. Current aspect of gastric cancer in Senegal: Epidemiological and clinical study of 220 cases. Dakar med 1996; 41: 99-103.

23. Ogutu EO, Lule GN, Okoth F, Musewe AO. Gastric carcinoma in Kenya African population. East Afr med J 1991; 68 :334-9.

24. Curado MP, Edwards B, Shin HR, Storm H, Ferlay $\mathrm{J}$, Heanue $\mathrm{M}$ et al. Cancer incidence in five continents Vol. IX. International Agency for Research on Cancer Lyon, France 2007;pg. 810-13.

25. Arfaoui D, Elloumi H, Hamila F, Gouma M, Ben Abdellaziz, Sfar S et al. Epidemiologic profile of gastric cancer: A study of 140 cases. Tunis med 2006; 84 : 301-4.

26. Matley PJ, Dent DM, Madden MV, Price SK. Gastric cancer in young Adults. Ann surg 1988; 208: 593-6.

27. Mandong BA, Mennaseh AN, Tanko MN, Echejor GO, Madaki A. Epidemiology of Gastric Cancer in Jos University Teaching Hospital Jos: A 20 year review of cases. Nigeria Journal of Medicine. Available at,http//:dx.doi.org/10.4314/njm.v19i4.61975.

28. Ojo OS. Ife-Ijesha cancer registry; In Parkin DM, Ferlay J, Hamdi-Cherif M, Sitas F, Thomas JO, Wabinga et al editors. Cancer in Africa: Epidemiology and Prevention. International Agency 
for Research on Cancer (IARC) Lyon 2003; pg 95.

29. Irabor DO, Afuwape OO. Malignant disease of stomach in Ibadan, Nigeria: A 19- year appraisal. East and central afr J surg 2012; 17(2):65-9.

30. Stomach cancer. American cancer society. Available at http://www.cancer.org/cancer/stomach cancer. Accessed on $18^{\text {th }}$ January 2015.

31. Subbiah V, Varadhachary G, Herzog CE. Gastric adenocarcinoma in children and adolescent. Paediatr Blood cancer 2011;57 (3): 524-7.

32. SEER cancer statistics Fact sheet: stomach cancer. National cancer institute. Bethesda, MD. Available at http://seer.cancer.gov/statfacts/html/stomach.html. Accessed 18th January2015.

33. Ferlay J, Shin HR, Bryan F, Forman D, Mathers C, Parkin DM. GLOBOCAN 2008 v2.0, Cancer Incidence and Mortality Worldwide: IARC Cancer Base No. 10. Lyon, France: International Agency for Research on Cancer, 2010. Available from http://globocan.iarc.fr.

34. Manzoor AD, Kursheed AW, Fazl QP, Rouf AW, Moh'd Lateef W, Peer GQ et al. Gastric cancer in young patients. Int J Surg Oncol 2013; 10: 155-9.

35. Shan Juan. Stomach cancer cases rises rapidly in China: Chinadaily.com.cn. Assessed 18 Feb. 2013.

36. Joseph BM, Mabula DM, Mheta K, Phillipo LC, Fabian M, Peter FR et al. Gastric cancer at a University teaching hospital; in NorthernmTanzania: A retrospective review of 232 cases. World J Surg Oncol 2012;10:257.

37. Kitoh T, Yamai H, Matsubara Y, Nakamura Y, Okamato T, Hirano A et al. Endoscopic findings potentially predictive of gastric cancer in borderline lesions diagnosed by forceps biopsy. Hepatogastroenterology 2005,52(62):404-8.

38.Sanna E, Nabil I, Hanane Z, Hanana E, Khalid H, Taib $\mathrm{K}$ et al. Epidemiological, clinical, pathological and therapeutic aspect of gastric cancer in Morocco. Clinical cancer Invest J 2014; 3 (1): 3-8

39. Office for National Statistics, Cancer Statistics registrations: Registrations of cancer diagnosed in
2008, England. Series MB1 No. 39. 2010, National Statistics: London.

40. Sun-Mi L, Kyoung-Mee K, Jae YR. Gastric carcinoma: Morphological classification and molecular changes. Available at http://dx.doi.org/10.5772/54617. Accessed on 18th January 2015.

41. Allaa HR, Sardar HA, Odesh YO, Sefar MH. Characterization of gastric malignancies and the trend of gastric carcinoma: A study of 155 cases between 2008 - 2013 in Duhork City-Iraq. Donnish J med and med sci 2014; 1(2): 12-7.

42. Zubin MB, Lara HT, Eduardo V, Deborah K, Mihat G, Manish AS et al. Stage- stratified prognosis of signet ring carcinoma histology in patients undergoing curative resection for gastric adenocarcinoma. Ann Surg Oncol 2014; 13: 3466-8.

43. Ikeda Y, Kosugi S, Nishikura K, Ohashi M, Kanda T, Kobayashi et al. Gastric carcinosarcoma presenting as a huge epigastric mass. Gastric cancer 2007; 10 : 63-8.

44. Uefuchi K, Ichikura T, Tamakuma S. Clinical prognostic characteristics of papillary clear carcinoma of stomach. Surg today 1996;26:158-63.

45. Hirota T, Ochia A, Habashi M, Maruyawa K. Significance of histological type of gastric carcinoma as a prognostic factor. Stom and intest 1999;26:1149-58.

46. Afuwape OO, Irabor DO, Ladipo JK, Ayandipo B. A review of the current profile of gastric cancer presentation in the University College Hospital Ibadan, a tertiary health care institution in the tropics. J Gastrointest. cancer 2012;43(2):177-80.

47. Togo A, Diakite I, Togo B, Coulibaly Y, Kante L, Dembele BT et al. Cancer gastrique au CHU Gabriel-Toure: Aspects epidemiologique et diagnostique. J Afr cancer 2011; 3: 227-31.

48. Biswas M, Rahi R, Tiwary Sk, Khanna R. Leiomyosarcoma of stomach: A case report. KUMJ 2006;4(4):510-12. 